\title{
HEURISTIC INSIGHTS ON GENDER EDUCATION
}

\section{Dr. Nimmi Maria Oommen}

Associate Professor of Education, Titus II Teachers College, Tiruvalla, Kerala

drnimmioommen@gmail.com; 9847347697(m).

\section{Dr. Suramya Mathai}

Assistant Professor in Social Science, Titus II Teachers College, Tiruvalla, Kerala. suramyamathai@gmail.com; 9562413413(m).

\section{ABSTRACT}

The Director-General for UNESCO, Audrey Azoulay remarked "Ignoring girls' education is akin to ignoring one of the most effective solutions for development," "When girls access quality education, it emboldens them to break the social stereotypes that hold back gender equality. It also gives them the tools to better navigate future life-altering choices on pregnancy, childbirth, and health challenges claiming millions of children's lives around the world. We cannot achieve the world we want without the education and empowerment of all girls and women."

The Global Education Monitoring (GEM) Report at UNESCO shows that if all women completed primary education, maternal deaths would be reduced by two-thirds. If they had a secondary education, child deaths would be cut by half, saving 3 million lives, and there would be two-thirds fewer child marriages. If all girls in sub-Saharan Africa, in South and West Asia had a secondary education, the number of pregnancies among girls younger than 17 would fall by close to $60 \%$. But slow progress is preventing girls from reaping all these benefits.

UNESCO unveils a new fact sheet on girls' education ahead of International Women's Day. The data is published as part of the 'HerEducationOurFuture' initiative which focuses on the progress achieved over the past 25 years. It shows that girls' enrolment rates in primary and secondary education have almost doubled in low-income countries, and that the gender gap in primary enrolment has been halved. But it also shows that the pace of change is not fast enough. At the present rate, getting every girl into primary school will only happen in 2050. Hence it is vital to focus on the key issues of gender responsive implementation of the 2030 agenda for Sustainable Development. This informative article presents some heuristic insights on gender education

Key words: Gender equality, equity, empowerment, 2030 Agenda 


\section{Introduction}

As you know, the 2030 Agenda represents the commitment of all of us to eradicate poverty, ensure prosperity for all, and protect our planet. Gender equality, and the empowerment of all women and girls are part of the 2030 Agenda and goals in their own right. They are also essential to any meaningful strategy to achieve all the other SDGs. It is by now well documented that any improvement along these dimensions of equality and empowerment spills over into positive benefits for many of the other goals and targets. Governments and all other stakeholders have started to implement the 2030 Agenda.

Gender equality "does not mean that women and men will become the same, but that women's and men's rights, responsibilities and opportunities will not depend on whether they are born male or female." That means there should be fairness of treatment for women and men, according to their respective needs. This may include equal treatment or treatment that is different, but which is considered equivalent in terms of rights, benefits, obligations, and opportunities.Let's look into the matter in depth. In no country women are equal. In fact, the World Economic Forum projects it will take 170 years to reach gender equality globally, and 158 years in North America. That means it will take five more generations for us to see gender equality - or my great, great, great, great, grandchildren may live in a nation with gender equality. That's not only a bad news for our daughters - it's bad news for our sons because gender equality impacts the economic pie for all.Many of the measures concerning gender equality interplay with the economy and more specifically, the workforce.

Let us see how equity leads to equality. If gender equity is about fairness, then what we are talking about here is making up for the gap between gender bias and reality. How can we hack the system to give women an equitable shot? Overall, gender mainstreaming is a very useful strategy. Because it overlays the gender lens across any action, policy and more.The concept recognizes that women and men have different needs and power and that these differences should be identified and addressed in a manner that rectifies the imbalances between the sexes. This may include equal treatment, or treatment that is different but considered equivalent in terms of rights, benefits, obligations and opportunities.

Though often used interchangeably, equality and equity are two very distinct concepts. While international human rights treaties refer to 'equality', in other sectors the term 'equity' is often used. The term 'gender equity' has sometimes been used in a way that perpetuates stereotypes about women's role in society, suggesting that women should be treated 'fairly' in accordance with the roles that they carry out. These understanding risks perpetuating to unequal gender relations and solidifying gender stereotypes that are detrimental to women. Therefore, the term should be used with caution to ensure it is not masking a reluctance to speak more openly about discrimination and inequality. 
Gender equality lies at the heart of the 2030 Agenda for Sustainable Development, which recognizes that achieving gender equality is a matter of human rights and is crucial to progress across all the goals and targets. While being a goal in its own right, gender equality cuts across all 17 Sustainable Development Goals and is reflected in 45 targets and 54 indicators for the SDGs. Furthermore, gender equality can be a catalytic policy intervention that triggers positive multiplier effects across the spectrum of development. Evidence collected from various sectors shows that gender equality is critical to achieving a wide range of objectives pertaining to sustainable development, from promoting economic growth and labour productivity, to reducing poverty and enhancing human capital through health and education, attaining food security, addressing climate change impacts and strengthening resilience to disasters, and ensuring more peaceful and inclusive communities. Based on this evidence, accelerating the pace of advancing gender equality in all spheres of society leads to a more rapid increase in progress towards the achievement of the 2030 Agenda.

Actions in the key areas are needed to accelerate progress to ensure equal rights, opportunities and outcomes for both women and men, to enhance women's agency, capabilities and participation in decision-making processes, to eliminate gender-based violence and discrimination and to transform power relations at all levels of society.

Achieving equality between women and men also requires institutionalizing a gender-responsive approach to financing, and ensuring that adequate investments are made to implement national plans and policies for gender equality and women's empowerment. These include, among others, promoting decent work, ensuring access to resources, reducing and redistributing unpaid care and domestic work, and strengthening social protection for all.

The systematic design and collection of and access to high-quality, reliable and timely genderdisaggregated data are essential to implementing effective and evidence-based policies. To advance gender equality, it is also important to implement and reinforce legal and institutional arrangements on gender equality, while strengthening accountability mechanisms for fulfilling existing commitments. This requires political will and stronger multi-stakeholder collaboration involving not only national and local governments, but also civil society, the private sector, academia and the media.

It is a fact that women are lagging behind in so many things whatever strategies and policies are adopted for them.Even in countries where women are strongly represented in Science, Technology, Engineering or Mathematics (STEM Education), they lag behind men in the workforce. The low participation of women in Science reflects the low female participation in the work force and the occupational gender segregation in the economy at large.Such anomalies require more discussions and when we observe the economic sector we can see the lower rates of women's participation in the labor force and a gender pay gap.In 2015, global average labor force participation was less than $50 \%$ for women as compared with $76 \%$ for men. As for young women it was only $37 \%$ compared with $54 \%$ for young men. It is high time to think about what 
can be done to remove the bottlenecks that inhibit the participation of women in the labour market.

Recent studies have shown that economic development alone does not automatically increase female labour force participation. Even if women enter labour force they are likely to go to lower paid occupations, reinforcing the gender pay gap. In this very country, women earn on an average of Rs.600for every Rs.900 earned by a man.Other reasons behind a gender pay gap include choice of working hours but also discrimination and bias against women in the workplace. How do we ensure that women are entering and participating in the labour market on equitable terms, and being paid the same amount for equal work within such setting?There are also other issues requiring high and immediate attention. Estimates show that $30 \%$ of women have been victims of gender-based violence in their lifetime, and harmful practices of female genital mutilation are still in place in at least 30 countries, in which around 1 in 3 girls aged 15 to 19 have undergone the practice. These are very diverse problems that we need to address.

SDG 5 of UNDP aims at ending all discrimination against women and girls. It is not only a basic human right, it's crucial for sustainable future. It is proven that empowering women and girls helps economic growth and development.

We need to focus on how to ensure progress on other goals which in turn gives maximal impact on SDG5. As a result of the efforts taken, we can see that there are more women than ever in the labour market. But there are still large inequalities in some regions, with women systematically denied the same work rights as men. Sexual violence and exploitation, the unequal division of unpaid care and domestic work, and discrimination in public office all remain huge barriers. All these issues are to be addressed. It is vital to give women equal rights to land and property, sexual and reproductive health, and to technology and the internet. Women are highly placed in different sectors than ever before. And it seems that encouraging more efficient women leaders will help achieve greater gender equality. We know where we need to go; and we definitely know why we need to get there. We need to identify the "how"; which strategies we need to put in place for a gender-responsive implementation of the 2030 Agenda.

\section{Conclusion}

The 2030 Agenda calls and reaffirms the immediate need for strategic plans for empowerment in all sectors. We need to devise deliberate methodologies and plan of action for gender empowerment, in particular women empowerment. Gender responsive measures should be prioritized locally with focus on global wellbeing. 


\section{References}

Araújo E. B., Araújo N. A., Moreira A. A., Herrmann H. J., \& Andrade J. S. Jr (2017). Gender differences in scientific collaborations: Women are more egalitarian than men. PloS one, 12(5), e0176791. Pmid: 28489872

Constantin, Andreea, Voicu, Malina. 2015. "Attitudes towards Gender Roles in Cross-Cultural Surveys: Content Validity and Cross-Cultural Measurement Invariance." Social Indicators Research 123(3):733-51.

Google Scholar | Crossref

Graham, Carol, Chattopadhyay, Soumya. 2013. "Gender and Well-Being around the World." International Journal of Happiness and Development 1(2):212-32. Google Scholar | Crossref

Shen H. (2013). Mind the gender gap. Nature, 495(7439), 22. Pmid:23467149

Oommen, N.M.(2016). Gender and Education: Insightful Gleanings. Attoor, Nvks Publishers.

United Nations Development Programme. 2010. Human Development Report 2010. Houndmills, UK: Palgrave Macmillan.

Google Scholar | Crossref

The SDGs in Action: The UNDP Report, Retrieved from https://www.undp.org/sustainabledevelopment-goals

Gender gap in primary school enrolment halved over past 25 years. UNESCO Report 2020. Retrieved from https://en.unesco.org/news/gender-gap-primary-school-enrolment-halved-overpast-25-years.

2020 GEM Report - Inclusion and education. Retrieved from https://en.unesco.org/gem-report. 